ОЦЕНКА ОБЕСПЕЧЕННОСТИ ВИТАМИНАМИ-АНТИОКСИДАНТАМИ ПАЦИЕНТОВ С ОЖИРЕНИЕМ С ПОЗИЦИЙ РИСКА РАЗВИТИЯ СОПУТСТВУЮЩИХ ЗАБОЛЕВАНИЙ

\author{
() В.М. Коденцова ${ }^{1 *}$, О.А. Вржесинская', О.В. Кошелева', Н.А. Бекетова', Х.Х. Шарафетдинов ${ }^{1,2,3}$
}

'Федеральный исследовательский центр питания, биотехнологии и безопасности пищи, Москва, Россия; ²Российская медицинская академия непрерывного профессионального образования, Москва, Россия; ${ }^{3}$ Первый Московский государственный медицинский университет имени И.М. Сеченова, (Сеченовский университет) Москва, Россия

Обоснование. Синхронно оптимизированные концентрации витаминов С, Е, каротиноидов и их соотношения в плазме крови способствуют предотвращению или замедлению развития многих алиментарно-зависимых заболеваний и их осложнений.

Цель. Охарактеризовать витаминный статус пациентов с ожирением с позиций риска прогрессирования имеющихся и развития сопутствующих заболеваний.

Методы. Проведено обсервационное одноцентровое поперечное исследование обеспеченности витаминами-антиоксидантами 81 пациента (21 мужчина, 60 женщин) 20-75 лет с индексом массы тела 40,7士1,2 кг/м², поступивших с апреля по июнь на лечение в ФИЦ питания и биотехнологии. Была определена в сыворотке крови концентрация а- и $ү$-токоферолов, аскорбиновой кислоты, $\beta$-каротина и рассчитаны их соотношения с показателями липидного профиля.

Результаты. Показатели витаминного статуса были определены у 35 пациентов с ожирением, 27 пациентов с избыточной массой тела или ожирением и сердечно-сосудистыми заболеваниями (СС3), 19 пациентов с ожирением и сахарным диабетом 2 типа (СД2). Концентрация аскорбиновой кислоты более чем у 50\% пациентов не достигала оптимального уровня (50 мкмоль/л). По сравнению с пациентами других групп пациенты с СД2 были лучше обеспечены витамином Е, но хуже - другими витаминами. У них неоптимальное соотношение концентраций витамина С и Е выявлялось чаще по сравнению с пациентами других групп (p $\leq 0,050)$. Среди них в 1,6-1,8 раза чаще выявлялась сочетанная неоптимальная обеспеченность витамином С и $\beta$-каротином (<0,4 мкмоль/л). Недостаток антиоксидантов у пациентов с Сд2 по критериям соотношения витаминов $\mathrm{C} / \mathrm{E}(>1,5)$ и уровню $\beta$-каротина обнаруживался чаще в 3,3 раза, C/E и витамина C в 2,4 раза. Уровень $\gamma$-токоферола в сыворотке крови пациентов с СД2 имел тенденцию к повышению по сравнению с таковым у пациентов с ожирением $(p=0,063)$ и СС3 $(p=0,081)$, концентрационное отношение $\gamma$-токоферол/холестерин (XC) было выше в 1,5 раза (соответственно $p=0,009$ и p=0,076). Лишь у 2 пациентов с ожирением и 2 пациентов с СС3 все показатели сыворотки крови соответствовали оптимальной обеспеченности всеми витаминами. По показателю а-токоферол/ХС (<5 мкмоль/ммоль) повышенный риск возникновения инфаркта миокарда имели от 10,5 до 42,9\% обследованных пациентов. Выявлена прямая связь между уровнем глюкозы и содержанием в сыворотке крови а- и ү-токоферолов, а также индивидуальных токоферолов, соотнесенных с ХС, и обратная связь между гликемией и индивидуальными токоферолами, соотнесенными с триглицеридами, а также с $\beta$-каротином и величиной C/E.

Заключение. У большинства пациентов обнаружено неоптимальное содержание витаминов в сыворотке крови по одному или нескольким параметрам. Пациентам с СД2 для оптимизации соотношения витаминов С и $\mathrm{E}$ необходимо увеличить потребление витамина С. Повышение уровня $\beta$-каротина в сыворотке крови и достижение оптимального соотношения C/E будут способствовать предотвращению повышения гликемии.

КЛЮЧЕВЫЕ СЛОВА: витамины-антиоксиданты; неоптимальная концентрация; сыворотка крови; соотнесенная с холестерином концентрация а-токоферола; триглицериды; ожирение.

\title{
ANTIOXIDANT VITAMIN STATUS OF OBESE PATIENTS IN TERMS OF THE RISK OF COMORBIDITIES
}

(c) Vera M. Kodentsova ${ }^{1 *}$, Oksana A. Vrzhesinskaya', Olga V. Kosheleva', Nina A. Beketova', Khaider K. Sharafetdinov ${ }^{1,2,3}$

${ }^{1}$ Federal Research Centre of Nutrition, Biotechnology and Food Safety, Moscow, Russia;

${ }^{2}$ Russian Medical Academy of Post-Graduate Education, Moscow, Russia;

3.M. Sechenov First Moscow State Medical University, Moscow, Russia

BACKGROUND: Synchronously optimized concentrations of vitamins C, E, A, carotenoids and their ratios in blood plasma help to prevent or slow down the development of many alimentary-dependent diseases and their complications.

AIMS: to characterize the vitamin status of obese patients from the standpoint of the risk of progression of existing and development of associated diseases.

MATERIALS AND METHODS: An observational single-site cross-sectional study of the sufficiency with antioxidant vitamins in 81 patients ( 21 men, 60 women) aged 20-75 years with body mass index 40,7 $71,2 \mathrm{~kg} / \mathrm{m}^{2}$, enrolled for treatment from April to June in Federal Research Centre of Nutrition, Biotechnology had been conducted. The concentration of $\alpha$ - and $\gamma$-tocopherols, retinol, ascorbic acid, $\beta$-carotene was determined in blood serum and their ratios with lipid profile were calculated.

*Автор, ответственный за переписку / Corresponding author. 
RESULTS: Indicators of vitamin status were determined in 35 patients with obesity, 27 patients with obesity and cardiovascular diseases (CVD), 19 patients with obesity and type 2 diabetes mellitus (T2DM). The concentration of ascorbic acid in more than $50 \%$ of patients did not reach the optimal level $(50 \mu \mathrm{mol} / \mathrm{l})$. Compared to patients of other groups, patients with T2DM were better supplied with vitamin $\mathrm{E}$, but worse with other vitamins. They have a non-optimal ratio of concentrations of vitamin $\mathrm{C}$ and E more often compared with patients of other groups $(p \leq 0.050)$. Among them, the combined suboptimal level of vitamin $C$ and $\beta$-carotene $(<0.4 \mu \mathrm{mol} / \mathrm{l})$ was detected 1.6-1.8 fold more often. The lack of antioxidants in patients with T2DM according to simultaneously reduced vitamin $\mathrm{C} /$ vitamin $\mathrm{E}$ ratio $(<1.5)$ and $\beta$-carotene level was detected 3.3-fold more often, synchronously lowered vitamin C/vitamin E ratio and vitamin C level - 2.4-fold. $\gamma$-tocopherol level in serum of patients with T2DM tended to increase compared with that in patients with obesity $(p=0.063)$ and CVD $(p=0.081), \gamma$-tocopherol/triacylglycerides ratio was 1.5 -fold higher (respectively $\mathrm{p}=0.009$ и $\mathrm{p}=0.076$ ). Only in 2 patients with obesity and 2 patients with CVD all serum indicators corresponded to the optimal level of all vitamins. In terms of a-tocopherol/cholesterol $(<5 \mu \mathrm{mol} / \mathrm{mol})$, an increased risk of myocardial infarction was detected in $10.5-42.9 \%$ of the examined patients. Glucose level was positively associated with serum levels of $a$ - and $\gamma$-tocopherols, as well as cholesterol-adjusted individual tocopherols; while glycemia was inversely associated with triacylglycerides-standardized individual tocopherols, as well as $\beta$-carotene and vitamin C/vitamin E ratio.

CONCLUSIONS: In most patients, a non-optimal serum vitamin content was found according to one or several parameters. In order to vitamin C/vitamin E ratio, patients with T2DM need to increase vitamin C intake. Increasing serum $\beta$-carotene and achieving an optimal $\mathrm{C} / \mathrm{E}$ ratio will help to prevent an increase in glycemia.

KEYWORDS: antioxidants; vitamins; suboptimal concentration; serum; cholesterol-adjusted a-tocopherol; triacylglycerides; obesity.

\section{ОБОСНОВАНИЕ}

Сердечно-сосудистые заболевания (СС3) и сахарный диабет 2 типа (СД2) относятся к заболеваниям, ассоциированным с ожирением [1], распространенность которого неуклонно увеличивается. В настоящее время проблемам оптимального питания, способного предотвращать или замедлить развитие многих алиментарно-зависимых заболеваний, уделяется пристальное внимание. Все чаще витамины рассматриваются не только с позиции эссенциальности, но и функциональности [2]. В этой связи предпринимаются попытки установить уровни разных форм витаминов в крови, необходимых не только для выполнения общепризнанной витаминной функции того или иного витамина, но и дополнительных, ранее неизвестных функций, обеспечивающих снижение риска развития алиментарно-зависимых заболеваний [3-5]. Показательным примером является витамин D. Установлено, что концентрация циркулирующей формы витамина D - 25-гидроксивитамина D - в сыворотке крови более 50 нмоль/л (по данным Российской ассоциации эндокринологов более 75 нмоль/л [6]) обеспечивает оптимальное функционирование многих зависящих от витамина D биохимических процессов, благодаря чему он поддерживает не только нормальное состояние костно-мышечной системы, но и способствует снижению риска развития ряда заболеваний, включая кальцификацию сосудов [7].

Имеются данные о том, что необходимое для предотвращения определенных видов рака, СС3 и других хронических заболеваний потребление различных токолов, включая а-токоферол, должно быть намного выше, чем суточная рекомендуемая норма потребления, обеспечивающая выполнение витаминной функции витамина E $[4,5]$. Описаны потенциальные эффекты токоферолов на функциональное состояние организма, собственно функцию витамина Е выполняет а-токоферол, тогда как $\mathrm{\gamma}$-токоферол, метаболизируясь цитохромом Р450 в длинноцепочечные карбоксихроманолы, обладает выраженным противовоспалительным действием [4]. По некоторым данным, уровень $ү$-токоферола в плазме крови служит биомаркером риска развития рака и СС3 [8]. От соотношения $а$ - и $ү$-токоферола в плазме крови зависит интенсивность проявления аллергического воспаления $[9,10]$. Отношение (в мкмоль/ммоль) a-токоферол/холестерин (а-токоферол/ХC) и ү-токоферол/холестерин ( $ү$-токоферол/ХC) положительно коррелирует с массой висцерального жира и наличием метаболического синдрома [11]. Вместе с тем показано, что при чрезмерно высоком потреблении а-токоферола он начинает проявлять прооксидантные свойства, смещает равновесие с другими природными пищевыми антиоксидантами и изоформами витамина E [9-11].

Предполагается, что низкий уровень а-токоферола при наличии дислипидемии может быть связан с ранними признаками атеросклероза [12]. В литературе имеются указания на то, что снижение уровня основного витамера витамина $\mathrm{E}$ - а-токоферола в сыворотке крови менее 4,2 мкмоль на 1 ммоль ХС ассоциируется с повышенным риском развития инфаркта миокарда [13], что согласуется с данными других авторов, показавших, что при коронарной болезни сердца концентрация а-токоферола, соотнесенная с XС и липидами, не превышает соответственно 4,8 мкмоль/ммоль и 2,66 мкмоль/ммоль [14].

Синхронно оптимизированные концентрации витамина С, а-токоферола, витамина А и каротиноидов в плазме крови необходимы для предотвращения СС3 и онкозаболеваний [15]. Поддержание антиоксидантного статуса требует оптимального соотношения а-токоферола и аскорбиновой кислоты, поскольку восстановление радикалов а-токоферола происходит под действием аскорбиновой кислоты [16]. Концентрация антиатерогенного ХС липопротеинов высокой плотности (ЛПВП) положительно коррелирует не только с уровнем $\beta$-каротина в сыворотке крови больных СС3, но и с содержанием других каротиноидов (а-каротин, криптоксантин) [17].

Особое значение витамина С при ожирении заключается в его антиоксидантном и противовоспалительном действии, в супрессии цитокинов, аномально секретируемых адипоцитами, предотвращении аномального накопления жира за счет снижения уровня свободных радикалов, а также уменьшения неферментативного гликозилирования, уменьшения перекисного окисления липидов [18]. 
Уровни в сыворотке крови, обеспечивающие профилактику ССЗ и онкозаболеваний, для витамина Е составляют $\geq 30$ мкмоль/л при соотношении а-токоферол/XC $\geq 5,0$ мкмоль/ммоль; витамина $C \geq 50$ мкмоль/л при концентрационном соотношении витамин С/витамин $\mathrm{E}>1,3-1,5$; $\beta$-каротина $\geq 0,4$ мкмоль/л или суммы $\alpha$ - и $\beta$-каротинов $\geq 0,5$ мкмоль/л $[15,19]$.

Однако имеются лишь единичные исследования, оценивающие одновременно обеспеченность пациентов витаминами-антиоксидантами с использованием критериев оптимального статуса $[15,17,19]$.

\section{ЦЕЛЬ}

Целью работы было охарактеризовать витаминный статус пациентов с ожирением и другими алиментарно-зависимыми заболеваниями с позиций риска прогрессирования имеющихся и развития сопутствующих заболеваний.

\section{МЕТОДЫ}

\section{Дизайн исследования}

Проведено обсервационное одноцентровое поперечное выборочное, неконтролируемое исследование.

\section{Критерии соответствия}

Критериями включения в исследование был возраст от 20 до 75 лет. Диагноз сопутствующей неалкогольной жировой печени в стадии жирового гепатоза устанавливался на основании признаков жирового гепатоза при ультразвуковом исследовании печени, нормальной активности аланинаминотрансферазы в сыворотке крови, отсутствия критериев невключения.

Критериями невключения были возраст моложе 20 и старше 75 лет, наличие ВИЧ-инфекции, вирусного гепатита В или С, гриппа, аллергических заболеваний.

\section{Условия проведения}

Исследование проводили с апреля по июнь 2018 г. на базе 3 отделений (сердечно-сосудистой патологии, болезней обмена веществ и профилактической и реабилитационной диетологии) Клиники лечебного питания ФИЦ питания и биотехнологии. Все инструментальные, клинические и биохимические исследования были проведены на базе одного учреждения.

\section{Продолжительность исследования}

Продолжительность исследования 3 месяца.

\section{Описание медицинского вмешательства}

Всем участникам исследования однократно производили забор крови натощак с последующим центрифугированием и замораживанием образцов сыворотки крови. Все участники исследования получали стандартную для каждой нозологии фармакотерапию: пациенты с CС3 - ингибиторы ангиотензинпревращающего фермента или блокаторы рецепторов ангиотензина II, бета-блокаторы, диуретики; пациенты с СД2 - комбинированную пероральную сахароснижающую терапию метформином, ингибиторами дипептидилпептидазы-4, ингибиторами натрий-глюкозных котранспортеров 2-го типа.
Основной исход исследования

Конечными точками исследования была концентрация витаминов и липидный спектр сыворотки крови во всех группах пациентов.

\section{Дополнительные исходы исследования}

Определяли количество лиц в каждой группе с одновременно сниженными относительно оптимального уровня парами показателей обеспеченности витаминами, а также количество пациентов с показателями, соответствующими оптимальному уровню по всем используемым параметрам, и не оптимально обеспеченных витаминами по нескольким показателям.

\section{Анализ в подгруппах}

Формирование подгрупп осуществлялось по основной нозологии и полу, по степени ожирения.

\section{Методы регистрации исходов}

Для определения витаминов кровь из вены, взятую натощак после ночного голодания, центрифугировали в течение 15 мин при 600 g, затем отбирали аликвоты сыворотки для определения каждого витамина, замораживали и хранили при температуре $-37,4^{\circ} \mathrm{C}$.

Концентрацию а- и ү-токоферолов, $\beta$-каротина определяли с помощью обращенно-фазовой высокоэффективной жидкостной хроматографии [20], аскорбиновой кислоты - визуальным титрованием реактивом Тильманса. Для витамина Е использовали также принятые за рубежом нормативы, а именно - снижение концентрации а-токоферола менее чем 12 мкмоль/л считали дефицитом, лиц с концентрацией, превышающей 30 мкмоль/л, относили к оптимально обеспеченным [19]. Для более точного определения статуса витамина Е у пациентов с гиперлипидемией и триглицеридемией рассчитывали соотношение a- и ү- токоферолов с концентрацией ХС и триглицеридов (ТГ) и их суммой (ХС+ТГ), считая, что оптимальной обеспеченности соответствует концентрация а-токоферола 5,0 мкмоль/ммоль ХС, а нормальному статусу витамина E - 6,79 мкмоль/ммоль ТГ или 2,66 мкмоль/ммоль ХС+ТГ $[14,15,19,21]$. В качестве критерия, отражающего оптимальную обеспеченность организма витамином С, использовали величину $\geq 50$ мкмоль/л при соотношении витамин С/витамин $\mathrm{E}$ (C/E) >1,5, $\beta$-каротином - концентрацию $\geq 0,4$ мкмоль/л [15].

Показатели липидного обмена (общий XС, ХC липопротеидов низкой плотности (ЛПНП) и ХС ЛПВП, ТГ) определяли в сыворотке крови с использованием биохимического анализатора Konelab 30i фирмы Thermo Clinical Labsystems (Финляндия).

\section{Этическая экспертиза}

Протокол исследования был одобрен комитетом по этике ФИЦ питания и биотехнологии (№2 от 02.03.2018 г). От всех участников обследования было получено письменное информированное согласие.

\section{Статистический анализ}

Размер выборки предварительно не рассчитывался.

Результаты обрабатывали с помощью программ IBM SPSS Statistics для Windows (версия 20.0 IBM, США). Для характеристики вариационного ряда рассчитывали 
Таблица 2. Концентрация витаминов-антиоксидантов в сыворотке крови пациентов

\begin{tabular}{|c|c|c|c|c|}
\hline Показатель & Min - Max & Me & 25-75 перцентиль & $\mathbf{p}$ \\
\hline \multicolumn{5}{|c|}{ 1. Пациенты с ожирением (n=35) } \\
\hline Токоферолы, мкмоль/л & $12,5-46,9$ & 26,3 & $20,9-32,8$ & - \\
\hline а-Токоферол, мкмоль/л & $12,1-45,5$ & 25,5 & $20,2-32,0$ & - \\
\hline ү-Токоферол, мкмоль/л & $0,14-1,42$ & 0,55 & $0,41-0,65$ & - \\
\hline а-Токоферол/ү-токоферол & $26,5-172,5$ & 50,0 & $37,5-63,7$ & \\
\hline а-Токоферол/ТГ, мкмоль/ммоль & $7,0-38,1$ & 15,6 & $12,3-19,4$ & - \\
\hline ү-Токоферол/ТГ, мкмоль/ммоль & $0,08-0,87$ & 0,35 & $0,21-0,48$ & - \\
\hline а-Токоферол/ХС, мкмоль/ммоль & $2,9-9,4$ & 5,2 & $4,3-6,5$ & - \\
\hline ү-Токоферол/ХС, мкмоль/ммоль & $0,02-0,33$ & 0,10 & $0,08-0,14$ & - \\
\hline а-Токоферол/ХС+ТГ, мкмоль/ммоль & $2,4-6,8$ & 3,9 & $3,2-4,5$ & - \\
\hline 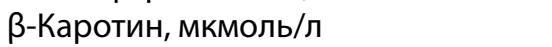 & $0,02-0,79$ & 0,17 & $0,11-0,30$ & - \\
\hline Аскорбиновая кислота, мкмоль/л & $12,7-107,9$ & 46,3 & $35,4-61,0$ & - \\
\hline $\mathrm{C} / \mathrm{E}$ & $0,3-4,7$ & 1,9 & $1,4-2,2$ & - \\
\hline \multicolumn{5}{|c|}{ 2. Пациенты с СС3 (n=27) } \\
\hline Токоферолы, мкмоль/л & $9,1-67,2$ & 25,9 & $20,0-30,4$ & - \\
\hline ж & $9,8-67,2$ & 27,1 & $22,1-31,2$ & - \\
\hline M & $9,1-30,5$ & $18,6^{0,084}$ & $14,4-28,3$ & - \\
\hline а-Токоферол, мкмоль/л & $8,8-65,2$ & 25,3 & $19,7-29,3$ & - \\
\hline ж & $9,3-65,2$ & 26,7 & $21,6-30,7$ & - \\
\hline M & $8,8-29,7$ & $18,1^{0,075}$ & $13,9-28,2$ & - \\
\hline ү-Токоферол, мкмоль/л & $0,22-1,97$ & 0,48 & $0,38-0,67$ & - \\
\hline ж & $0,29-1,97$ & 0,48 & $0,40-0,67$ & - \\
\hline M & $0,22-0,84$ & 0,47 & $0,31-0,71$ & - \\
\hline а-Токоферол/ ү-токоферол & $17,6-93,0$ & 45,0 & $32,7-62,9$ & \\
\hline а-Токоферол/ТГ, мкмоль/ммоль & $7,1-44,9$ & 16,9 & $12,9-26,4$ & - \\
\hline ж & $9,3-44,9$ & 21,3 & $15,4-30,7$ & - \\
\hline M & $7,1-32,7$ & $14,6^{0,051}$ & $8,0-18,6$ & - \\
\hline ү-Токоферол/ТГ, мкмоль/ммоль & $0,11-1,43$ & 0,43 & $0,29-0,54$ & $p_{1-2}=0,041$ \\
\hline а-Токоферол/ХС, мкмоль/ммоль & $2,5-8,9$ & 5,6 & $4,7-6,5$ & - \\
\hline ү-Токоферол/ХС, мкмоль/ммоль & $0,07-0,33$ & 0,11 & $0,09-0,15$ & - \\
\hline а-Токоферол/ХС+ТГ, мкмоль/ммоль & $2,1-5,7$ & 4,5 & $3,7-4,9$ & - \\
\hline 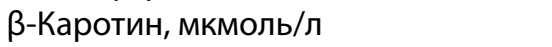 & $0,03-2,38$ & 0,25 & $0,10-0,55$ & - \\
\hline Аскорбиновая кислота, мкмоль/л & $9,7-71,8$ & 49,5 & $37,7-59,9$ & - \\
\hline $\mathrm{C} / \mathrm{E}$ & $0,3-5,9$ & 2,0 & $1,3-2,6$ & - \\
\hline
\end{tabular}

$\mathrm{C} / \mathrm{E}$

3. Пациенты с сахарным диабетом 2 типа $(\mathbf{n}=19)$

\begin{tabular}{|c|c|c|c|c|}
\hline Токоферолы, мкмоль/л & $16,9-97,2$ & 31,0 & $25,9-38,4$ & $\begin{array}{l}p_{1-3}=0,052 \\
p_{2-3}=0,019\end{array}$ \\
\hline а-Токоферол, мкмоль/л & $16,5-95,2$ & 30,0 & $25,5-37,6$ & $\begin{array}{l}p_{1-3}=0,005 \\
p_{2-3}=0,016\end{array}$ \\
\hline ү-Токоферол, мкмоль/л & $0,34-2,02$ & 0,63 & $0,46-0,86$ & $\begin{array}{l}\mathrm{p}_{1-3}=0,063 \\
\mathrm{p}_{2-3}=0,081\end{array}$ \\
\hline а-Токоферол/ ү-токоферол & $27,7-76,0$ & 47,2 & $36,2-57,7$ & \\
\hline а-Токоферол/ТГ, мкмоль/ммоль & $6,7-46,4$ & 13,5 & $12,0-18,4$ & $p_{2-3}=0,092$ \\
\hline ү-Токоферол/ТГ, мкмоль/ммоль & $0,14-0,72$ & 0,33 & $0,25-0,40$ & $p_{2-3}=0,035$ \\
\hline а-Токоферол/ХС, мкмоль/ммоль & $3,1-15,5$ & 6,8 & $5,8-8,8$ & $\begin{array}{l}\mathrm{p}_{1-3}=0,002 \\
\mathrm{p}_{2-3}=0,009\end{array}$ \\
\hline ү-Токоферол/ХС, мкмоль/ммоль & $0,08-0,33$ & 0,16 & $0,11-0,18$ & $\begin{array}{l}\mathrm{p}_{1-3}=0,009 \\
\mathrm{p}_{2-3}=0,076\end{array}$ \\
\hline а-Токоферол/ХС+ТГ, мкмоль/ммоль & $2,2-6,8$ & 4,8 & $4,1-5,7$ & $\begin{array}{l}\mathrm{p}_{1-3}=0,010 \\
\mathrm{p}_{2-3}=0,084\end{array}$ \\
\hline $\beta$-Каротин, мкмоль/л & $0,03-0,97$ & 0,15 & $0,06-0,30$ & $p_{2-3}=0,080$ \\
\hline ж & $0,04-0,97$ & 0,16 & $0,09-0,36$ & - \\
\hline M & $0,03-0,29$ & $0,05^{0,034}$ & $0,03-0,18$ & - \\
\hline Аскорбиновая кислота, мкмоль/л & $13,4-63,8$ & 38,1 & $31,5-52,3$ & - \\
\hline $\mathrm{C} / \mathrm{E}$ & $0,4-2,4$ & 1,1 & $0,9-1,8$ & $\begin{array}{l}p_{1-3}=0,013 \\
p_{2-3}=0,027\end{array}$ \\
\hline
\end{tabular}

Примечание: Верхний индекс - статистическая значимость отличия от показателя у женщин, C/E - концентрационное соотношение аскорбиновой кислоты и а-токоферола. 
в сыворотке крови а-токоферола, а также его концентрация, соотнесенная с ХС. Такие параметры, как концентрация а-токоферола, привязанная к концентрации суммы ХС и ТГ, имели тенденцию к повышению. У половины пациентов с СД2 концентрация а-токоферола достигала величины, соответствующей оптимальной обеспеченности организма этим витамином. Таким образом, пациенты с СД2 были лучше обеспечены витамином Е по сравнению с пациентами других групп. У них большинство параметров обеспеченности витамином E, за исключением параметра а-токоферол/ТГ, соответствовали оптимальным.

ү-Токоферол составлял примерно 2\% от содержания а-токоферола в сыворотке крови пациентов из всех групп. Вместе с тем уровень $ү$-токоферола в сыворотке крови пациентов с СД2 имел тенденцию к повышению по сравнению с таковым у пациентов с ожирением и СС3, концентрационное отношение ү-токоферол/ХС было выше в 1,5 раза (соответственно $\mathrm{p}=0,009$ и $\mathrm{p}=0,076)$.

Дефицит витамина Е, оцениваемый по концентрации a-токоферола, соотнесенной с ТГ, не выявлялся. Соотношение а-токоферола с концентрацией ХC+TГ оказалось малоинформативным, недостаточная обеспеченность витамином E по этому показателю выявлялась редко, составляя от 5,3 до 8,6\%, поэтому на рис. 1 эти данные не представлены.

По показателю а-токоферол/ХС повышенный риск возникновения сердечно-сосудистых осложнений (инфаркт миокарда [13]) имели от 10,5 до 42,9\% обследованных пациентов.
Концентрация аскорбиновой кислоты более чем у $50 \%$ пациентов не достигала оптимального уровня. У пациентов с СД2 медиана концентрации аскорбиновой кислоты была самой низкой (табл. 2), а частота неоптимального уровня, наоборот, самой высокой (рис. 1), хотя различия и не достигали уровня статистической значимости. В результате неоптимальное отношение концентраций витаминов C и E (C/E) у этой категории больных выявлялось статистически значимо чаще по сравнению с пациентами других групп ( $p<0,050)$.

Более чем у $3 / 4$ пациентов из всех групп концентрация $\beta$-каротина в сыворотке крови не достигала оптимального уровня (см. рис. 1), при этом более чем у половины пациентов с ожирением и СД2 и 40\% пациентов с СС 3 она не достигала нижней границы нормы.

\section{Дополнительные результаты исследования}

Далее было оценено количество лиц с одновременно сниженными относительно оптимального уровня парами показателей обеспеченности витаминами (табл. 3). Частоты выявления пар показателей, не достигающих оптимального уровня обеспеченности, среди пациентов с ожирением и СС3 значимо не различались, тогда как доли пациентов с СД2 отличались от них как в большую, так и в меньшую сторону. Среди них в 1,6-1,8 раза чаще выявлялась сочетанная неоптимальная обеспеченность витамином С и $\beta$-каротином. У этой же категории больных одновременная неоптимальная обеспеченность природными антиоксидантами по критериям C/E и концентрации $\beta$-каротина обнаруживалась в 3,3 раза чаще, по критерию C/E и концентрации витамина C - в 2,4 раза.

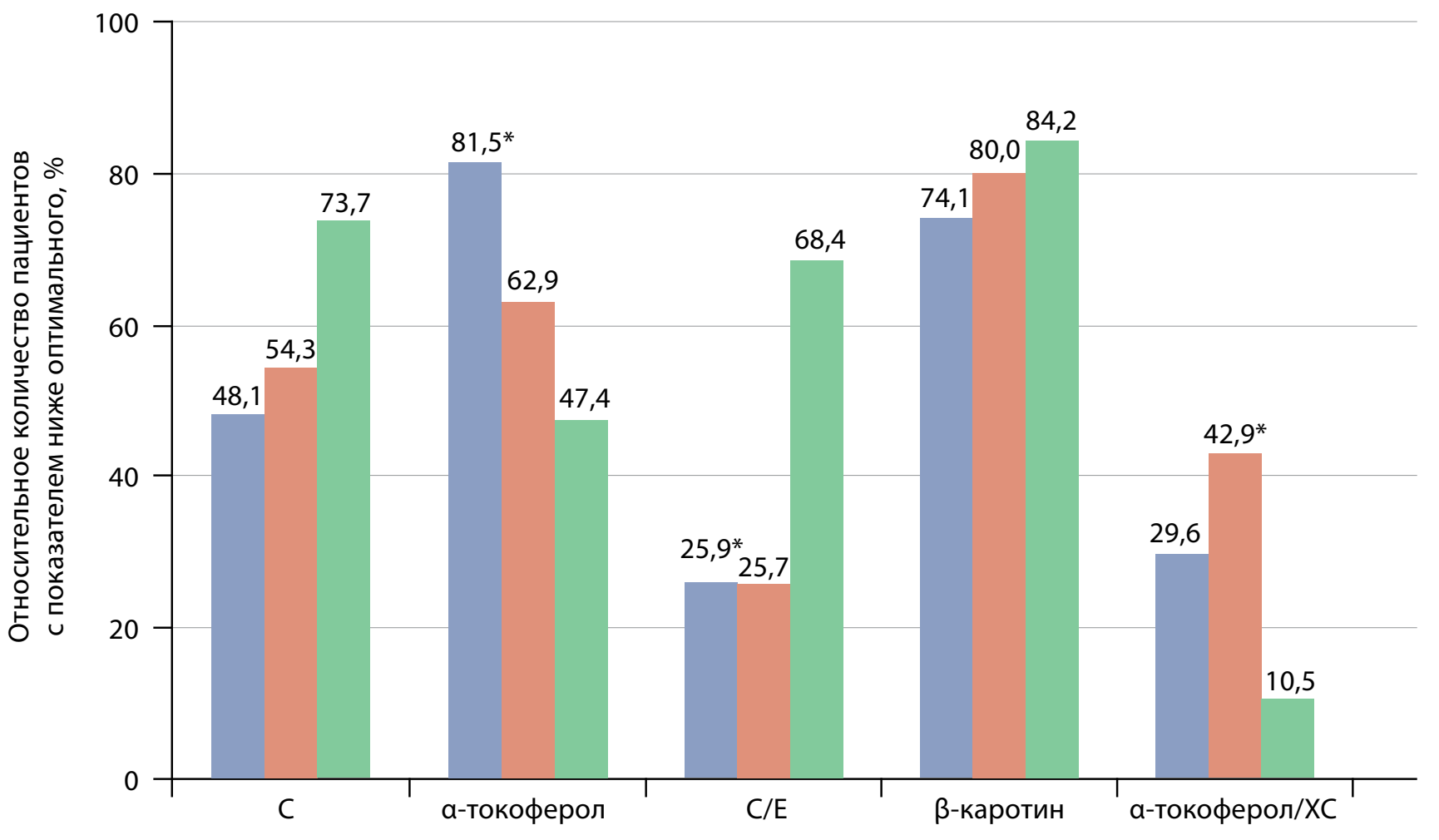

CC3 ожирение

СД 2 типа

Рисунок 1. Количество пациентов с показателями, не достигающими оптимальных величин. * - статистически значимые отличия $(p<0,05)$ от показателя пациентов с СД2 согласно критерию Фишера 
Таблица 3. Относительное количество лиц с одновременно сниженными относительно оптимального уровня парами показателей обеспеченности витаминами, \%

\begin{tabular}{|c|c|c|c|c|}
\hline \multicolumn{2}{|c|}{ Пара показателей } & Ожирение & CC3 & СД2 \\
\hline \multirow{4}{*}{$\mathrm{C}$} & а-токоферол & 40,0 & 40,7 & 36,8 \\
\hline & $C / E$ & 25,7 & 25,9 & $63,2^{1,2}$ \\
\hline & a-токоферол/XC & 28,6 & 18,5 & $5,3^{1}$ \\
\hline & $\beta$-каротин & 45,7 & 40,7 & $73,7^{1,2}$ \\
\hline \multirow{3}{*}{ а-Токоферол } & $C / E$ & 11,4 & 14,8 & 26,3 \\
\hline & а-токоферол/XC & 40,0 & 29,6 & $10,5^{1}$ \\
\hline & $\beta$-каротин & 51,4 & 55,6 & 36,8 \\
\hline \multirow{2}{*}{$C / E$} & $\beta$-каротин & 20,0 & 22,2 & $68,4^{1,2}$ \\
\hline & а-токоферол/XC & 8,6 & 3,7 & 5,3 \\
\hline$\beta$-Каротин & а-токоферол/XC & 42,9 & 22,2 & $10,5^{1}$ \\
\hline
\end{tabular}

Статистически значимые отличия ( $<<0,05)$ от частоты выявления согласно критерию Фишера:

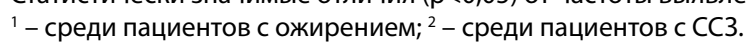

Таким образом, и при таком подходе к анализу данных было обнаружено, что у лиц с СД2 чаще по сравнению с пациентами из других групп выявляется неоптимальная обеспеченность витамином С и $\beta$-каротином.

На следующем этапе было оценено количество лиц с витаминным статусом, соответствующим оптимальному уровню, по всем используемым параметрам, и неоптимально обеспеченных витаминами-антиоксидантами одновременно по нескольким показателям (рис. 2).
Лишь у 2 пациентов с ожирением и 2 пациентов с СС3 все показатели сыворотки крови соответствовали оптимальной обеспеченности (см. рис. 2). У 2 человек с СД2 $(10,5 \%)$ и 5 пациентов с СС3 (18,5\%), за исключением концентрации а-токоферола в сыворотке крови, которая превысила 25 мкмоль/л, остальные показатели также находились на оптимальном уровне. На рисунке 2 видно, что вся гистограмма для больных СД2 сдвинута вправо относительно гистограмм для других групп пациентов,

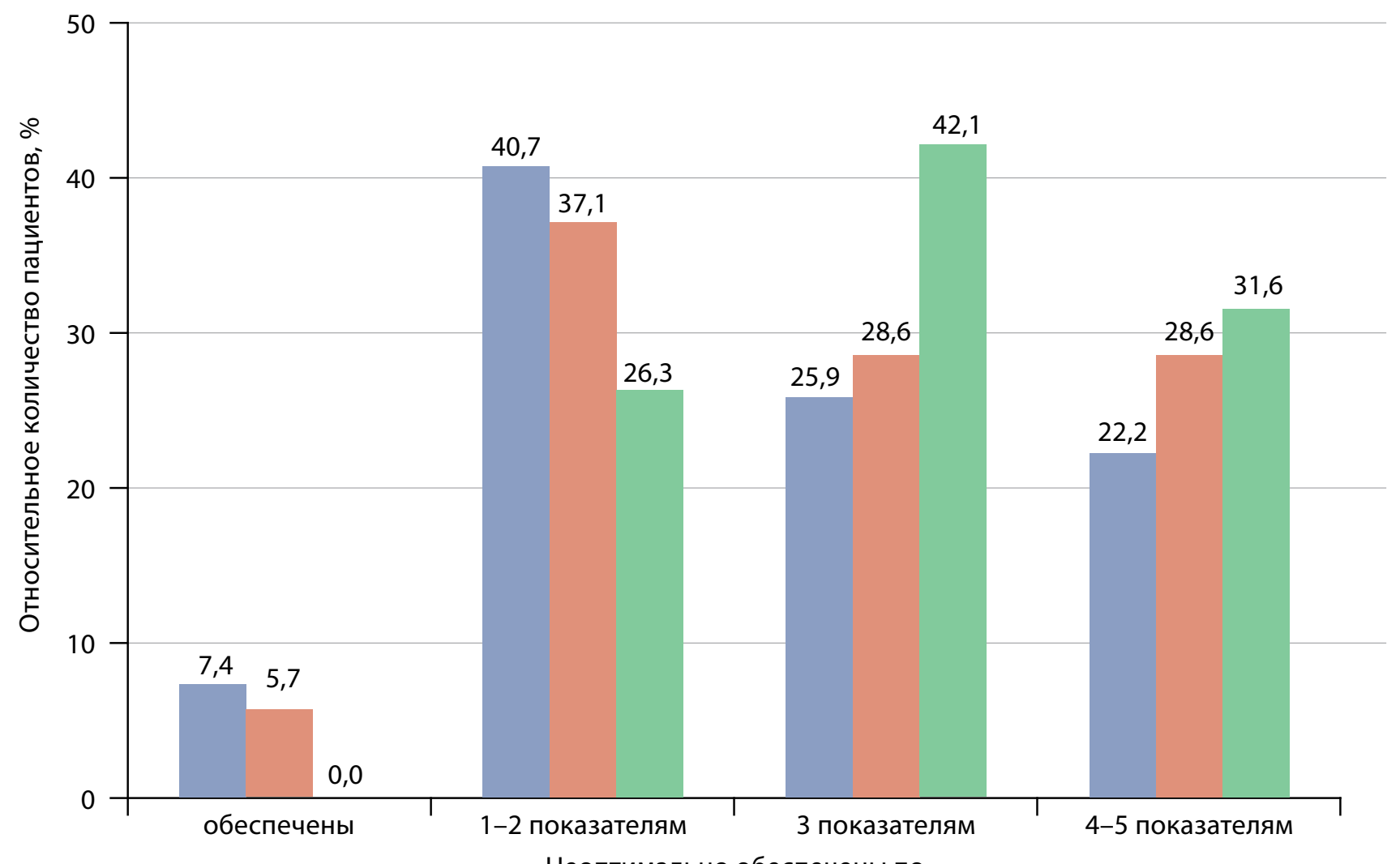

Неоптимально обеспечены по 
Таблица 4. Коэффициенты корреляции Спирмена между концентрацией витаминов в сыворотке крови всех пациентов $(\mathrm{n}=81, \mathrm{p} \leq 0,01)$

\begin{tabular}{|c|c|c|}
\hline \multicolumn{2}{|c|}{ Пара показателей } & \multirow{2}{*}{$\begin{array}{c}\boldsymbol{\rho} \\
0,464\end{array}$} \\
\hline$C$ & $\beta$-каротин & \\
\hline$c$ & а-токоферол & 0,296 \\
\hline \multirow{4}{*}{$\beta$-Каротин } & $C / E$ & $0,263^{*}$ \\
\hline & а-токоферол/ТГ & 0,742 \\
\hline & ү-токоферол/ТГ & 0,542 \\
\hline & а-токоферол/ТГ+ХС & 0,389 \\
\hline \multirow{3}{*}{ а-Токоферол } & ү-токоферол & 0,610 \\
\hline & ү-токоферол/XС & 0,356 \\
\hline & Ү-токоферол/ТГ+ХС & 0,309 \\
\hline \multirow{3}{*}{ ү-Токоферол } & C/E & $-0,425$ \\
\hline & а-токоферол/XC & 0,447 \\
\hline & а-токоферол/ТГ+ХС & 0,326 \\
\hline
\end{tabular}

$*-p \leq 0,050$

хотя различия долей не достигли уровня статистической значимости. Это означает, что в целом группа пациентов с СД2 была хуже обеспечена витаминами-антиоксидантами (в основном за счет витамина С) по сравнению с лицами из других групп.

Между концентрацией витаминов-антиоксидантов, в том числе нормализованных по содержанию липидов, в сыворотке крови всех пациентов выявлена положительная корреляция (табл. 4). Между соотнесенными концентрациями аскорбиновой кислоты и а-токоферола (C/E) и уровнем $\gamma$-токоферола обнаружена отрицательная связь.

Выявлена положительная корреляция (табл. 5) между абсолютным содержанием а- и ү-токоферолов и липидным спектром крови (XС, ТГ). Концентрация $\beta$-каротина и аскорбиновой кислоты обнаруживает обратную связь с уровнем ТГ, а между уровнем $\beta$-каротина и антиатерогенными ЛПВП выявляется прямая связь.

Обнаружена прямая связь между уровнем глюкозы и содержанием в сыворотке крови а- и ү-токоферолов, а также индивидуальных токоферолов, соотнесенных с ХC, и обратная между гликемией и индивидуальными токоферолами, соотнесенными с ТГ, а также с $\beta$-каротином и величиной C/E (см. табл. 5).

При делении каждой группы пациентов на подгруппы лиц с ИМТ $<40$ кг $/ \mathrm{M}^{2}$ и ИМТ $>40$ кг/M² статистически значимых различий по концентрации витаминов в плазме крови среди пациентов с СД2 и с ожирением в качестве основного диагноза обнаружено не было.

В то же время, несмотря на малую выборку пациентов, при анализе показателей витаминного статуса в зависимо-

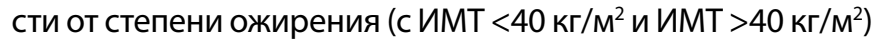
удалось выявить некоторые закономерности у пациентов с СС3. Пациенты с СС3 и морбидным ожирением (ИМТ $<40$ кг/м²) были хуже обеспечены пищевыми антиоксидантами: частота выявления неоптимального уровня $\beta$-каротина в плазме крови у них была в 2,4 раза $(p \leq 0,05)$ выше, чем у пациентов из подгруппы с ИМТ <40 кг/м², а соотнесенные с ТГ концентрации а- и $ү$-токоферолов были ниже соответственно в $2(p \leq 0,001)$ и 1,8 раза $(p=0,006)$.
Таблица 5. Парные коэффициенты корреляции Спирмена между концентрацией витаминов и биохимическими показателями сыворотки крови всех пациентов $(\mathrm{n}=81, \mathrm{p} \leq 0,010)$

\begin{tabular}{|c|c|c|}
\hline \multicolumn{2}{|c|}{ Пара показателей } & $\rho$ \\
\hline \multirow{4}{*}{ а-Токоферол } & $X C$ & 0,496 \\
\hline & лПнП & 0,441 \\
\hline & ТГ & 0,501 \\
\hline & глюкоза & 0,276 \\
\hline \multirow{3}{*}{ а-Токоферол/ТГ } & глюкоза & $-0,353$ \\
\hline & ЛПВП & 0,704 \\
\hline & ИМТ & $-0,429$ \\
\hline \multirow{4}{*}{ а-Токоферол/XС } & глюкоза & $0,245^{*}$ \\
\hline & лПнП & $-0,303$ \\
\hline & ТГ & 0,362 \\
\hline & возраст & $0,243^{*}$ \\
\hline \multirow{4}{*}{ ү-Токоферол } & $\mathrm{XC}$ & 0,291 \\
\hline & ТГ & 0,400 \\
\hline & глюкоза & $0,269^{*}$ \\
\hline & возраст & 0,320 \\
\hline \multirow{3}{*}{ ү-Токоферол/ТГ } & глюкоза & $-0,271$ \\
\hline & лПВП & 0,731 \\
\hline & ИМТ & $-0,329$ \\
\hline \multirow{4}{*}{ ү-Токоферол/XС } & глюкоза & $0,262^{*}$ \\
\hline & лПнП & $-0,264$ \\
\hline & ТГ & 0,285 \\
\hline & возраст & 0,345 \\
\hline \multirow{4}{*}{$\beta$-Каротин } & ЛПВП & 0,574 \\
\hline & $\mathrm{T \Gamma}$ & $-0,523$ \\
\hline & глюкоза & $-0,293$ \\
\hline & имт & $-0,416$ \\
\hline Витамин C & $\mathrm{T \Gamma}$ & $-0,245^{*}$ \\
\hline \multirow{4}{*}{$C / E$} & $X C$ & $-0,423$ \\
\hline & лПнП & $-0,373$ \\
\hline & ТГ & $-0,488$ \\
\hline & глюкоза & $-0,304$ \\
\hline
\end{tabular}

$*-p \leq 0,050$

Нежелательные явления

Нежелательных явлений в ходе исследования ни в одной из трех групп отмечено не было.

\section{ОБСУЖДЕНИЕ}

Принципиальным отличием данного исследования от традиционной оценки обеспеченности витаминами с использованием критериев дефицита витаминов (нижней границы нормальной обеспеченности) является использование критериев оптимальной обеспеченности каждым витамином. Кроме того, достоинством данного исследования является синхронная характеристика витаминного статуса одновременно несколькими витаминами-антиоксидантами, к тому же соотнесенными с показателями липидного обмена. 
За исключением соотношения а-токоферол/ТГ другие соотнесенные с липидами показатели обеспеченности витамином Е соответствовали оптимальным. Это может быть как следствием использования заниженного критерия, который, по всей видимости, отражает не оптимальный статус, а дефицит витамина Е, так и следствием повышенного уровня ТГ у пациентов с СД2.

Выявленные положительные ассоциации между уровнями витаминов в сыворотке крови, а также между концентрацией витаминов и биохимическими показателями необязательно отражают непосредственную причинно-следственную связь и могут быть обусловлены вмешивающимися факторами. Однако обнаружение таких связей указывает на целесообразность синхронной оптимизации витаминного статуса.

\section{Резюме основного результата исследования}

Лишь у 2 пациентов с ожирением и 2 пациентов с СС3 все показатели сыворотки крови соответствовали оптимальной обеспеченности всеми исследованными витаминами. У подавляющего большинства пациентов обнаружено неоптимальное содержание витаминов-антиоксидантов в сыворотке крови по одному или нескольким параметрам. Чаще всего заметные отклонения показателей витаминной обеспеченности от оптимальных имели место у пациентов с СД2.

\section{Обсуждение основного результата исследования}

Соотношение $а$ - и $ү$-токоферолов в сыворотке крови пациентов составило 50:1, что выше по сравнению с таковым у жителей Германии (23:1) [22].

Всем пациентам требуется обогащение рациона $\beta$-каротином. Подавляющему большинству пациентов с СД2 для повышения концентрации аскорбиновой кислоты в сыворотке крови необходимо увеличить потребление витамина С, что в конечном счете приведет к оптимизации соотношения витаминов C и E, тогда как пациентам из других групп необходимо увеличить потребление как витамина $C$, так и витамина Е. Повышение уровня $\beta$-каротина в сыворотке крови и достижение оптимального соотношения C/E будут способствовать предотвращению повышения гликемии.

Выявленная положительная корреляция (см. табл. 5) между абсолютными концентрациями изоформ токоферолов и ХС, а также ТГ в значительной мере может отражать функциональную связь между этими параметрами, поскольку токоферолы циркулируют в крови в составе липидных компонентов.

Между концентрацией $\beta$-каротина и антиатерогенными ЛПВП выявляется прямая связь (см. табл. 5). Обнаруженная обратная связь между уровнями глюкозы и индивидуальных токоферолов, соотнесенных с ТГ, $\beta$-каротина, а также величиной C/E (см. табл. 5) свидетельствует о важности повышения уровня $\beta$-каротина и достижения оптимального соотношения C/E для предотвращения повышения гликемии, увеличивающейся с возрастом у обследованных лиц $(\rho=0,290, n=81, p \leq 0,01)$, и ИMT $(\rho=0,348, n=81, p \leq 0,01)$.

\section{Ограничения исследования}

Ограничением данного исследования явилось небольшое количество обследованных пациентов в каждой выборке и широкий возрастной диапазон.

\section{ЗАКЛЮЧЕНИЕ}

Для оценки витаминного статуса организма соотнесенные с показателями липидного обмена уровни токоферолов в крови применяются сравнительно редко. В большинстве исследований используют критерии, отражающие не оптимальную обеспеченность организма тем или иным витамином, а дефицит микронутриента. Практически не описаны данные по использованию синхронно оптимизированных концентраций витаминов-антиоксидантов.

Сравнение обеспеченности пациентов с позиций риска прогрессирования осложнений заболеваний с использованием критериев оптимальной обеспеченности витаминами-антиоксидантами показало, что группы лиц с ожирением и ССЗ оказались сопоставимыми между собой. В то же время у пациентов с СД2 концентрация в сыворотке крови а-токоферола была выше, а аскорбиновой кислоты ниже по сравнению с другими группами пациентов. Среди пациентов с СД2 статистически значимо чаще выявлялась сочетанная неоптимальная обеспеченность витамином C и $\beta$-каротином, а также обнаруживалось неоптимальное соотношение витаминов С и Е. При оценке с использованием частот совпадения сразу нескольких признаков неоптимальной обеспеченности пациенты с СД2 также оказались хуже обеспечены витаминамиантиоксидантами по сравнению с лицами из других групп.

Использование нескольких параметров для оценки обеспеченности витаминами-антиоксидантами оказалось полезным для выявления неоптимальной обеспеченности этими микронутриентами. Такой подход позволяет индивидуально подходить к коррекции витаминного состава рациона пациентов, чтобы достичь оптимальных соотношений, обеспечивающих снижение риска развития алиментарно-зависимых заболеваний и их осложнений. Кроме того, использование такого подхода будет полезным при подборе эффективных доз витаминов-антиоксидантов, которые часто используются в необоснованно избыточных дозах, смещающих равновесие с другими природными антиоксидантами.

Для оптимизации витаминного статуса пациентам с СД2 необходимо увеличить содержание в их рационе витамина $C$ для повышения соотношения витаминов С и Е до оптимального, а также $\beta$-каротина путем увеличения потребления свежих овощей и фруктов - источников этих микронутриентов, или назначения этим пациентам содержащих эти микронутриенты витаминных комплексов в дозах, соответствующих рекомендуемому потреблению. Причем чем более выражено ожирение, тем в большей степени пациент нуждается в увеличении потребления каротиноидов. Пациентам с ожирением и с СС3, помимо перечисленных микронутриентов, необходимо увеличить потребление и витамина Е, содержащегося в больших количествах в подсолнечном масле.

\section{ДОПОЛНИТЕЛЬНАЯ ИНФОРМАЦИЯ}

Источник финансирования. Научно-исследовательская работа проведена за счет средств субсидии на выполнение государственного задания по теме «Изучение витаминной обеспеченности, характеристика кишечной микробиоты и разработка системы диетической коррекции алиментарно-зависимых заболеваний, в частности ожирения, 
у детей и взрослых» № 0529-2019-0062 без привлечения дополнительного финансирования со стороны третьих лиц.

Конфликт интересов. Авторы декларируют отсутствие явных и потенциальных конфликтов интересов, связанных с публикацией настоящей статьи.

Участие авторов. Коденцова В.М. - концепция и дизайн исследования, написание текста (общее руководство, интерпретация полученных данных, написание статьи, выводы, анализ данных литературы); Вржесинская О.А. - концепция и дизайн исследования, статистическая обработка, редактирование; Шарафетдинов Х.X. - сбор материала (подбор пациентов, сбор анамнеза, обработка амбулаторных карт), редактирование; Бекетова Н.А. - получение и обработка материала (определение токоферолов и $\beta$-каротина); Кошелева О.В. - получение и обработка материала (определение витамина С), статистическая обработка. Все авторы внесли значимый вклад в проведение исследования и подготовку статьи, прочли и одобрили финальную версию статьи перед публикацией.

Благодарности. Авторы Выражают благодарность Пилипенко В.И., Косюра С.Д, Гаппаровой К.М., Дербеневой С.А. за помощь в сборе исходного материала, включая анамнез и обработку амбулаторных карт.

\section{СПИСОК ЛИТЕРАТУРЫ | REFERENCES}

1. Дедов И.И., Мельниченко Г.А., Шестакова М.В., и др. Национальные клинические рекомендации по лечению морбидного ожирения у взрослых. 3-й пересмотр (лечение морбидного ожирения у взрослых) // Ожирение и метаболизм. 2018. - T. 15. — № 1. - C. 53-70. [Dedov II, Melnichenko GA, Shestakova MV, et al. Russian national clinical recommendations for morbid obesity treatment in adults. 3rd revision (Morbid obesity treatment in adults). Obesity and metabolism. 2018;15(1):53-70. (In Russ.)] doi: https://doi.org/10.14341/omet2018153-70

2. Bischoff-Ferrari H. Vitamin D - from essentiality to functionality. Int J Vitam Nutr Res. 2012;82(5):321-326. doi: https://doi.org/10.1024/0300-9831/a000126

3. Коденцова В.М. Современные тенденции в витаминологии // Вопросы питания. - 2018. - T. 87. - № S5. - С. 59-60. [Kodentsova VM. Sovremennye tendentsii v vitaminologii. Problems of nutrition. 2018;87(S5):59-60. (In Russ.)] doi: https://doi.org/10.24411/0042-8833-2018-10145

4. Shahidi F, de Camargo AC. Tocopherols and Tocotrienols in Common and Emerging Dietary Sources: Occurrence, Applications, and Health Benefits. Int J Mol Sci. 2016;17(10). doi: https://doi.org/10.3390/ijms17101745

5. Gast GC, de Roos NM, Sluijs I, et al. A high menaquinone intake reduces the incidence of coronary heart disease. Nutr Metab Cardiovasc Dis. 2009;19(7):504-510 doi: https://doi.org/10.1016/j.numecd.2008.10.004

6. Дедов И.И., Мельниченко Г.А., Пигарова Е.А., и др. Дефицит витамина D у взрослых: диагностика, лечение и профилактика. Клинические рекомендации. - М.: Российская ассоциация эндокринологов; 2015. [Dedov II, Mel'nichenko GA, Pigarova EA, et al. Defitsit vitamina D u vzroslykh: diagnostika, lechenie i profilaktika. Klinicheskie rekomendatsii. Moscow: Rossiyskaya assotsiatsiya endokrinologov; 2015. (In Russ.)]

7. Hossein-nezhad A, Holick MF. Vitamin D for health: a global perspective. Mayo Clin Proc. 2013;88(7):720-755. doi: https://doi.org/10.1016/.mayocp.2013.05.011

8. Mathur P, Ding Z, Saldeen T, Mehta JL. Tocopherols in the Prevention and Treatment of Atherosclerosis and Related Cardiovascular Disease. Clin Cardiol. 2015;38(9):570-576. doi: https://doi.org/10.1002/clc.22422

9. Cook-Mills J, GebretsadikT, Abdala-Valencia H, et al. Interaction of vitamin $\mathrm{E}$ isoforms on asthma and allergic airway disease. Thorax. 2016;71(10):954-956. doi: https://doi.org/10.1136/thoraxjnl-2016-208494

10. McCary CA, Abdala-Valencia H, Berdnikovs S, Cook-Mills JM. Supplemental and highly elevated tocopherol doses differentially regulate allergic inflammation: reversibility of alpha-tocopherol and gamma-tocopherol's effects. J Immunol. 2011;186(6):3674-3685. doi: https://doi.org/10.4049/jimmunol.1003037

11. Waniek S, di Giuseppe R, Plachta-Danielzik S, et al. Association of Vitamin E Levels with Metabolic Syndrome, and MRI-Derived Body Fat Volumes and Liver Fat Content. Nutrients. 2017;9(10). doi: https://doi.org/10.3390/nu9101143
12. Miranda C, Duarte VHR, Cruz MSM, et al. Association of Serum Alpha-Tocopherol and Retinol with the Extent of Coronary Lesions in Coronary Artery Disease. J Nutr Metab. 2018;2018:6104169. doi: https://doi.org/10.1155/2018/6104169

13. Cangemi R, Pignatelli P, Carnevale R, et al. Cholesteroladjusted vitamin $E$ serum levels are associated with cardiovascular events in patients with non-valvular atrial fibrillation. Int J Cardiol. 2013;168(4):3241-3247. doi: https://doi.org/10.1016/j.ijcard.2013.04.142

14. Mebazaa A, Mechmeche R, Alcindor LGr, et al. Vitamin E and Coronary Heart Disease in Tunisians. Clin Chem. 2000;46(9):1401-1405. doi: https://doi.org/10.1093/clinchem/46.9.1401

15. Gey KF. Vitamins E plus $C$ and interacting conutrients required for optimal health. A critical and constructive review of epidemiology and supplementation data regarding cardiovascular disease and cancer. Biofactors. 1998;7(1-2):113-174. doi: https://doi.org/10.1002/biof.5520070115

16. Traber MG. Mechanisms for the prevention of vitamin E excess. J Lipid Res. 2013;54(9):2295-2306. doi: https://doi.org/10.1194/jr.R032946

17. Бекетова Н.А., Дербенева С.А., Спиричев В.Б., и др. Обеспеченность антиоксидантами и показатели липидного спектра крови пациентов с сердечно-сосудистой патологией // Вопросы питания. - 2007. - Т. 76. — №3. - C. 11-18. [Beketova NA, Derbeneva SA, Spirichev VB, et al. Serum levels of antioxidants and lipid metabolism in patients with cardiovascular disease. Problems of nutrition. 2007;76(3):11-18. (In Russ.)]

18. Ellulu MS. Obesity, cardiovascular disease, and role of vitamin C on inflammation: a review of facts and underlying mechanisms. Inflammopharmacology. 2017;25(3):313-328. doi: https://doi.org/10.1007/s10787-017-0314-7

19. Peter S, Friedel A, Roos FF, et al. A Systematic Review of Global AlphaTocopherol Status as Assessed by Nutritional Intake Levels and Blood Serum Concentrations. Int J Vitam Nutr Res. 2015;85(5-6):261-281. doi: https://doi.org/10.1024/0300-9831/a000281

20. Якушина Л.М., Бекетова Н.А., Бендер Е.Д., Харитончик Л.А. Использование методов ВЭЖХ для определения витаминов в биологических жидкостях и пищевых продуктах // Вопросы питания. — 1993. - №1. - C. 43-48. [Yakushina LM, Beketova NA, Bender ED, Kharitonchik LA. Ispol'zovanie metodov VEZhKh dlya opredeleniya vitaminov v biologicheskikh zhidkostyakh i pishchevykh produktakh. Problems of nutrition 1993;(1):43-48. (In Russ.)]

21. Thurnham DI, Davies JA, Crump BJ, et al. The use of different lipids to express serum tocopherol: lipid ratios for the measurement of vitamin E status. Ann Clin Biochem. 1986;23(Pt 5):514-520. doi: https://doi.org/10.1177/000456328602300505

22. Waniek S, di Giuseppe R, Esatbeyoglu T, et al. Vitamin E (alpha- and gamma-Tocopherol) Levels in the Community: Distribution, Clinical and Biochemical Correlates, and Association with Dietary Patterns. Nutrients. 2017;10(1). doi: https://doi.org/10.3390/nu10010003

ИНФОРМАЦИЯ ОБ АВТОРАХ [AUTHORS INFO]:

*Коденцова Вера Митрофановна, д.б.н., профессор [Vera M. Kodentsova, BD, PhD in biology, Professor]; адрес: Россия, 109240, Москва, Устьинский пр-д, д. 2/14 [address: 2/14, Ustinskij pr., 109240, Moscow, Russia]; ORCID: http://orcid.org/0000-0002-5288-1132; eLibrary SPIN: 8470-1211; e-mail: kodentsova@ion.ru. 
Вржесинская Оксана Александровна, к.б.н. [Oksana A. Vrzhesinskaya, PhD in biology];

ORCID: http://orcid.org/0000-0002-8973-8153; eLibrary SPIN: 2745-1454; e-mail: vr.oksana@yandex.ru

Кошелева Ольга Васильевна [Olga V. Kosheleva]; ORCID: https://orcid.org/0000-0003-2391-9880;

eLibrary SPIN: 1667-2098; e-mail: kosheleva@ion.ru

Бекетова Нина Алексеевна, к.х.н. [Nina A. Beketova, PhD in chemistry];

ORCID: http://orcid.org/0000-0002-8973-8153; eLibrary SPIN: 6604-6431; e-mail: beketova@ion.ru

Шарафетдинов Хайдерь Хамзярович, д.м.н. [Khaider Kh. Sharafetdinov, MD, PhD];

ORCID: https://orcid.org/0000-0001-6061-0095; eLibrary SPIN: 1236-8210; e-mail: sharafandr@mail.ru

*Автор, ответственный за переписку / Corresponding author.

\section{ЦИТИРОВАТЬ:}

Коденцова В.М., Вржесинская О.А., Кошелева О.В., Бекетова Н.А., Шарафетдинов Х.Х. Оценка обеспеченности витаминами-антиоксидантами пациентов с ожирением с позиций риска развития сопутствующих заболеваний // Ожирение и метаболизм. - 2020. - Т. 17. - №1. - С. 22-32. doi: https://doi.org/10.14341/omet10144

\section{TO CITE THIS ARTICLE:}

Kodentsova VM, Vrzhesinskaya OA, Kosheleva OV, Beketova NA, Sharafetdinov KK. Antioxidant vitamin status of obese patients in terms of the risk of comorbidities. Obesity and metabolism. 2020;17(1):22-32. doi: https://doi.org/10.14341/omet10144 